\title{
Germ cell-specific Atg7 knockout results in primary ovarian insufficiency in female mice
}

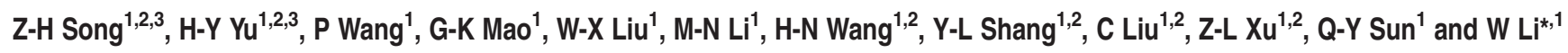

Primary ovarian insufficiency (POI) is a common cause of infertility in around $1-2 \%$ of women aged $<40$ years. However, the mechanisms that cause POI are still poorly understood. Here we showed that germ cell-specific knockout of an essential autophagy induction gene Atg7 led to subfertility in female mice. The subfertility of Atg7 deletion females was caused by severe ovarian follicle loss, which is very similar to human POI patients. Further investigation revealed that germ cell-specific Atg7 knockout resulted in germ cell over-loss at the neonatal transition period. In addition, our in vitro studies also demonstrated that autophagy could protect oocytes from over-loss by apoptosis in neonatal ovaries under the starvation condition. Taken together, our results uncover a new role for autophagy in the regulation of ovarian primordial follicle reservation and hint that autophagyrelated genes might be potential pathogenic genes to POI of women.

Cell Death and Disease (2015) 6, e1589; doi:10.1038/cddis.2014.559; published online 15 January 2015

Primary ovarian insufficiency (POI), also known as premature ovarian failure (POF), is an ovarian defect characterized by the premature depletion of ovarian follicles before the age of 40 years. $\mathrm{POI}$ is a common cause of infertility in women, affecting $1-2 \%$ of individuals aged $<40$ years and $0.1 \%$ of individuals aged $<30$ years. ${ }^{1}$ Potential etiologies for $\mathrm{POI}$ are highly heterogeneous, which include iatrogenic, infectious, autoimmune, metabolic, chromosomal and genetic factors. ${ }^{2}$ At present, about $25 \%$ of all forms of POF can be classified as iatrogenic and are related to cancer treatment, but $>50 \%$ of the cases remain idiopathic. Though the pathogenic mechanism remains unexplained in the majority of the cases, several observations support a prevalent role of genetic mechanisms in the pathogenesis of idiopathic $\mathrm{POI}$. It has been reported that mutations in FMR1, BMP-15, GDF-9, FOCL2, FSHR, LHR, INHA, GALT and AIRE are associated with $\mathrm{POI}^{3-13}$ The genetic information of $\mathrm{POI}$ is very useful for family counseling, because it can predict the female relatives who may be at higher risk for $\mathrm{POI}$ and fertility loss in young age. The female carriers will be able to plan their conception before ovarian failure occurs. This requirement is becoming more and more important, because women nowadays tend to conceive ever more frequently in their thirties and forties, ${ }^{10}$ when the risk of $\mathrm{POI}$ in the general population is about $1-2 \%$. However, still few genes could be identified that can explain a substantial proportion of the cases of $\mathrm{POI}$.

An important phenotype of $\mathrm{POI}$ is infertility, thus $\mathrm{POI}$ patients do not have large family histories, and therefore are difficult to study using traditional genetic methods, such as linkage analysis. Animal models of POI have been successfully used to identify candidate genes in this disease.
The disruption of meiosis-specific genes, Bcl-2 family apoptotic-related genes, Pten-PI3K-Akt-Foxo3 pathway and Tsc1/2-mTOR signaling pathway result in POI-like phenotype in mice. ${ }^{14-17}$ However, as a complex disorder, the genetic etiologies of $\mathrm{POI}$ still need to be further investigated to better understand the underlying molecular mechanisms.

Macroautophagy (hereafter referred to as autophagy) is the primary intracellular catabolic mechanism for degrading and recycling long-lived proteins and organelles, which is evolutionarily conserved from yeast to mammals. ${ }^{18}$ During autophagy, isolation membrane enwraps parts of the cytoplasm and intracellular organelles, and fuse with each other forming a double membrane structure, known as the autophagosome. Then the outer membrane of the autophagosome fuses with the lysosome to form autolysosome, in which the cytoplasmderived materials are degraded by resident hydrolases. ${ }^{19}$ The primary function of autophagy is to allow cells or organisms to survive nutrient starvation conditions by recycling either proteins or other cellular components. This process is important for cells to adapt their metabolism to starvation caused by decreased extracellular nutrients or by decreased intracellular metabolite concentrations. In addition to nutrient supply and adaptation to stress conditions, a number of observations have revealed that autophagy also functions in many physiological processes in mammalian systems, such as cell death, antiaging mechanisms, innate immunity, development and tumor suppression. ${ }^{20-25}$

From the discovery of the molecular mechanism underlying autophagy, it was found that autophagy is required for the reproductive process in budding yeast. ${ }^{26} \mathrm{In}$ mammals, fertilization induces massive autophagy to degrade maternal

\footnotetext{
${ }^{1}$ State Key Laboratory of Reproductive Biology, Institute of Zoology, Chinese Academy of Sciences, Beijing, PR China and ${ }^{2}$ University of Chinese Academy of Sciences, Beijing, PR China

${ }^{*}$ Corresponding author: W Li, State Key Laboratory of Reproductive Biology, Institute of Zoology, Chinese Academy of Sciences, 1 Beichen West Road, Chaoyang District, Beijing 100101, China. Tel: +86 10 64807529; Fax: +86 10 64806480; E-mail: leways @ioz.ac.cn

${ }^{3}$ These authors contributed equally to this work.

Abbreviations: Atg7, autophagy-related gene 7; LC3, microtubule-associated protein 1 light chain 3; POI, primary ovarian insufficiency; MVH, mouse vasa homolog; 3-MA, 3-methyladenine; TUNEL, TdT-mediated dUTP nick end labeling; dpc, day postcoitum; PI, propidium iodide

Received 04.9.14; revised 03.11.14; accepted 24.11.14; Edited by GM Fimia
} 
proteins and messenger RNAs, and autophagy functions as a major nutrient-providing system for embryos before their implantation. ${ }^{27}$ Our recent work indicates that autophagy is required for acrosome biogenesis during spermatogenesis in mice, thus essential to male fertility. ${ }^{24}$ However, whether autophagy is involved in female gametogenesis or not is still unknown. Here, we showed that germ cell-specific knockout of an essential autophagy induction gene Atg7 led to POI in female mice, and the numbers of the oocytes and follicles were significantly declined in the adult mutant mice. Further investigation revealed that autophagy protected oocytes overloss during the neonatal transition period. Our results suggest that autophagy-related genes might be pathogenic genes to POI.

\section{Results}

Generation of germ cell-specific $\operatorname{Atg} 7$ knockout female mice. The core molecular machinery of autophagy was driven by two ubiquitin-like conjugation systems, which are required for the autophagosome formation. Autophagyrelated gene 7 (Atg7) is the homologous of the ubiquitinactivating enzyme $E 1$, which is essential to both of these two conjugation systems. ${ }^{28}$ Because Atg7-deficient mice died within 1 day after birth, ${ }^{29}$ we cannot study its role in female reproduction directly, thus we generated a germ cell-specific $\operatorname{Atg} 7$ knockout mouse line by crossing $A \operatorname{tg} 7^{\mathrm{F} / F_{\text {mice }}}$ with transgenic mice expressing Tnap promoter-mediated Cre recombinase. In Tnap-Cre mice, Cre is expressed in primordial germ cells, ${ }^{30}$ and its expression resulted in germ cell-specific Atg7 knockout mice hereafter called Atg $7^{F / F}$; Tnap-cre. Figure 1a shows the genotyping of $A \operatorname{tg} 7^{F / F} ;$ Tnapcre mice.

Germ cell-specific Atg7 knockout causes subfertility due to follicles over-loss. To test the female fertility after germ cell-specific Atg7 knockout, a breeding assay was conducted by mating $A \operatorname{tg} T^{F / F}$ or $A \operatorname{tg} T^{F / F} ;$ Tnap-cre female mice with $A \operatorname{tg} T^{F / F}$ males for 6 months. As shown in Figure 1b, female $A \operatorname{tg} 7^{F / F}$; Tnap-cre mice were severely subfertile and gave birth to about $63 \%$ fewer pups than $A \operatorname{tg} 7^{F / F}$ mice $(14.80 \pm 2.332$ versus $40.33 \pm 8.686, P<0.05)$. Interestingly, all the five randomly selected $A \operatorname{tg} 7^{\mathrm{F} / \mathrm{F}} ;$ Tnap-cre females were fertile at their first conception, and they gave birth 7-8 pups at their first litter, which was similar to the $A \operatorname{tg} 7^{F / F}$ mice (Figure 1c). However, in the subsequent assessment, they suddenly gave significantly less pups per litter or became completely sterile. This phenotype was very similar to $\mathrm{POI}$ in human patients.

To explore the mechanism underlying the reproductive defects caused by $\operatorname{Atg} 7$ knockout, we further compared follicular development in 6-month-old $A \operatorname{tg} 7^{\mathrm{F} / \mathrm{F}} ;$ Tnap-cre with that in $A \operatorname{tg} 7^{F / F}$ mice. As shown in Figure 1d, although primordial, activated follicles and corpus luteum were found in 6-month ovaries of $A \operatorname{tg} 7^{F / F}$ and $A \operatorname{tg} 7^{F / F} ;$ Tnap-cre mice, the number of the follicles appeared to be reduced in the $A \operatorname{tg} 7^{F / F}$; Tnap-cre mice compared with the $A \operatorname{tg} 7^{\mathrm{F} / F}$ mice. To determine whether the deletion of Atg7 affected follicular development, we performed accurate counts of primordial and activated follicles. As shown in Figure 1e, the total number of the follicles was seriously reduced in the $A \operatorname{tg} 7^{\mathrm{F} / \mathrm{F}}$;Tnap-cre mice compared with the $A \operatorname{tg} 7^{F / F}$ mice $(106 \pm 9.866$ versus $401 \pm 31.75$, $P<0.05)$; the primordial follicles $(55 \pm 5.196)$ and activated follicles $(51 \pm 4.726)$ population in the $A \operatorname{tg} 7^{F / F} ;$ Tnap-cre mice had declined by $79 \%$ and $64 \%$, respectively, compared with that in the control group $(261.0 \pm 25.7,140 \pm 12.86, P<0.05)$. These histological results revealed that the number of follicles was severely affected by Atg7 deletion, especially for the primordial follicles, suggesting that the subfertility in female Atg7 knockout mice might be caused by the germ cell overloss.

Germ cell-specific Atg7 knockout leads to oocyte overloss during neonatal transition. In mammals, the profound cell loss occurs at birth in the ovary, which precedes the establishment of a fixed follicle reserve that is progressively depleted during the reproductive lifespan. To clarify the key stage for oocyte over-loss after Atg7 deletion, we examined the germ cell numbers by immunohistochemistry using a germ cell molecular marker mouse vasa homolog (MVH) in prenatal and postnatal $A \operatorname{tg} 7^{F / F} ;$ Tnap-cre ovaries. In 17.5-dpc (day postcoitum) ovaries, although the expression of an autophagy marker microtubule-associated protein 1 light chain 3 (LC3) ${ }^{31}$ decreased very significantly in Atg7 knockout ovary compared with that in the $A \operatorname{tg} 7^{F / F}$, no apparent difference was found in the morphological analysis between $A \operatorname{tg} 7^{F / F} ;$ Thap-cre and $A \operatorname{tg} 7^{F / F}$ (Figure 2c). The number of oocytes also showed no significant difference between $A \operatorname{tg} 7^{F / F}$; Tnap-cre $(4591 \pm 88.22)$ and $A \operatorname{Atg} 7^{F / F}(4365 \pm 195.7)$ (Figure 2d). Therefore, we further compared follicular development in 3-day-old Atg $7^{F / F} ;$ Tnap-cre mice to that in $A \operatorname{tg} 7^{F / F}$ mice. As shown in Figures $3 a$ and $b$, the expression of LC3 in Atg7 knockout ovary was clearly less than that in the control ovary. Different from those 17.5-dpc ovaries, the numbers of the oocytes $(1792 \pm 477.2)$ and follicles $(1498 \pm 470.7)$ in the $A \operatorname{tg} 7^{\mathrm{F} / F} ;$ Tnap-cre ovaries were significantly reduced compared with the $A \operatorname{tg} 7^{F / F}(3716 \pm 102.6,2930 \pm 175.2$, respectively), $52 \%$ oocytes and $49 \%$ follicles were lost after Atg7 knockout in germ cells (Figures $3 \mathrm{c}$ and d). These results suggested that Atg7 might be necessary for germ cells survival during the neonatal transition.

Autophagy is induced in the ovary of normal neonatal mice. Autophagy was induced in other organs during the early neonatal starvation period. ${ }^{32}$ To investigate whether the role of Atg7 is dependent on autophagy in the neonatal ovaries, we first examined the induction of autophagy by immunostaining the autophagy marker LC3. As shown in Figures $4 \mathrm{a}$ and $\mathrm{b}$, the autophagic activity was immediately induced in the neonatal ovaries and reached its maximal level during 3-6 $\mathrm{h}$ after birth and then gradually decreased to basal levels at around $24 \mathrm{~h}$. According to our observation, the neonatal mice began suckling at $1-2 \mathrm{~h}$ after birth, which is before the maximal autophagic activity time. To confirm that autophagy was induced by neonatal starvation, we separated the neonatal mice from the mother immediately after their birth, which can block their nutrients' supply from milk. Under non-suckling condition, the autophagic activity was upregulated in the neonatal ovaries and reached its maximal level during 3-6 $\mathrm{h}$ after birth and then maintained at a relative 
a

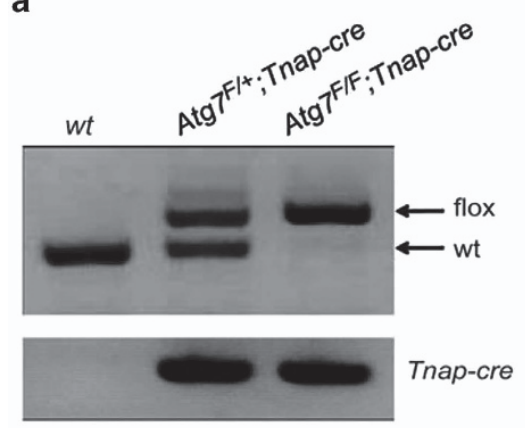

b

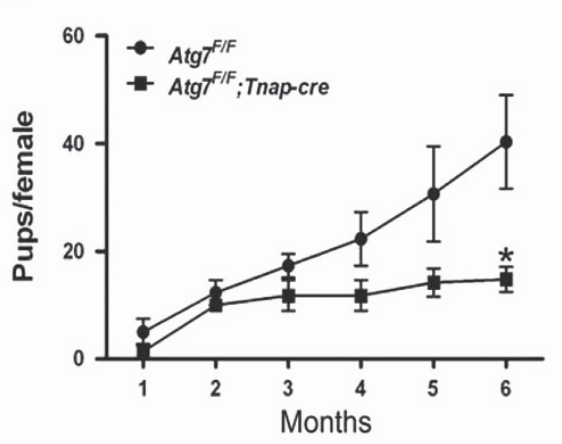

C

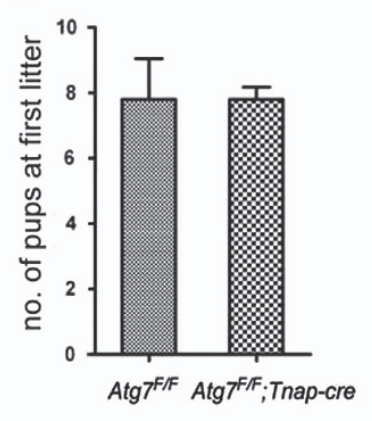

d

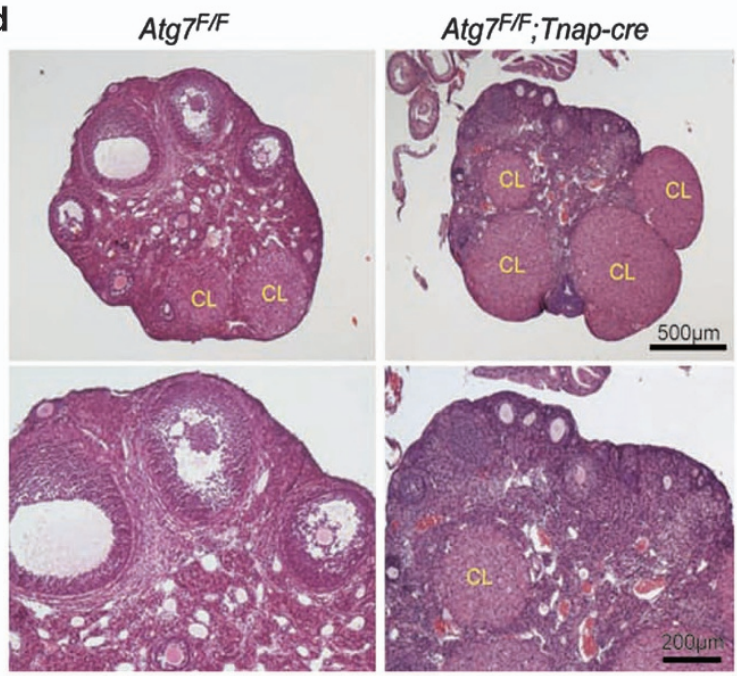

e

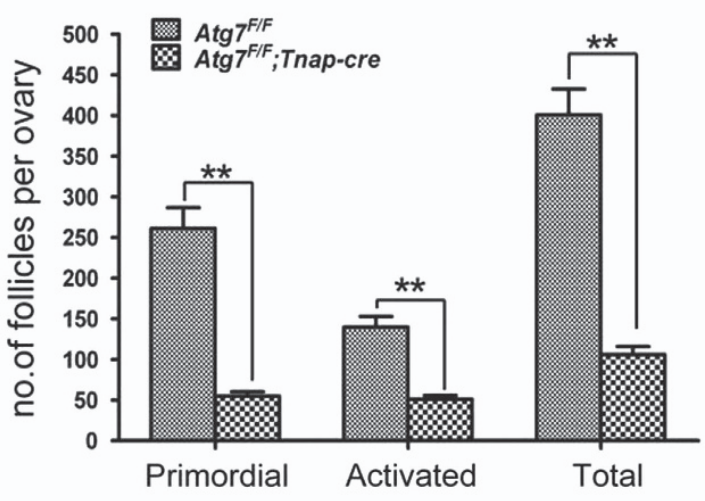

Figure 1 Disruption of Atg7 in oocytes led to female subfertility with follicle over-loss. (a) PCR confirmation of the Atg7/F;Tnap-cre mice. (b) Subfertility of the female Atg $7^{\mathrm{F} / F}$; Tnap-cre mice. Both $\operatorname{Atg}^{F^{F / F}}(n=6)$ and $\operatorname{Atg}^{F / F}$; Tnap-cre $(n=5)$ females were mated with wild-type males; continuous breeding assessment showed the cumulative number of progeny per female mouse. Asterisk indicates statistically significant difference in comparison with $A \operatorname{tg} 7^{F / F}$. (c) The first litter size of $A \operatorname{tg} 7^{F / F}(n=6)$ and $A \operatorname{tg} 7^{F / F} ; \operatorname{Tnap}-c r e(n=5)$ females. (d) Representative hematoxylin and eosin staining of ovaries from 6-month-old mice of each genotype. CL, corpus luteum. (e) Quantification of the follicle numbers in ovaries of $\operatorname{Atg}^{F / F}(n=6)$ and $A \operatorname{tg}{ }^{F / F}$;Tnap-cre $(n=5)$ mice at 6 months of age. Data are presented as the mean \pm S.E.M. ${ }^{*} P<0.05,{ }^{* *} P<0.01$

higher level compared with the normal neonatal mice under suckling condition (Figures $4 \mathrm{a}$ and b). In addition, 59\% neonatal mice under non-suckling condition died during 21-24 h (Figure 4c); the 24-h survivals were immediately killed for experiments. In order to address whether this nonsuckling starvation condition can lead to germ cell loss, survivors under the non-suckling condition were fed at $20 \mathrm{~h}$ and lived up to 3 days. As shown in Figures $4 d$ and e, this non-suckling starvation also caused a small-scale oocytes $(3156 \pm 123.6$ versus $3620 \pm 112.0, P<0.05)$ and follicles $(2315 \pm 191.6$ versus $2974 \pm 127.4, P<0.05)$ loss compared with the normal group. These results confirmed that autophagy is transiently induced in the ovaries of neonatal mice under physiological conditions.

Autophagy protects germ cell from over-loss in newborn ovaries. To address whether Atg7 alone or the whole autophagic machinery is functional in the neonatal mouse ovary, we established an in vitro culture system for neonatal ovaries to mimic the in vivo neonatal transition process. To accomplish this, ovaries from 18.5-dpc animals were firstly cultured in basic medium ${ }^{33,34}$ for $24 \mathrm{~h}$, after which the ovaries were treated with autophagy inhibitor 3-methyladenine
(3-MA) for autophagy inhibition. Ovaries were starved by incubating in PBS with $15 \%$ basic medium. Figure 5 a shows the diagram of autophagy inhibition and starvation treatment in the in vitro neonatal ovary culture system. After replacing the $85 \%$ basic medium with PBS (85\% PBS group), the level of LC3 was significantly increased compared with the group under nutrient condition (DMEM+FBS group), which indicated that autophagy was drastically induced in the neonatal ovaries after the nutrient deprivation (Figures $5 b$ and $c$ ). In addition, the number of oocytes $(1919 \pm 170.7)$ and follicles $(939.3 \pm 46.94)$ in the $85 \%$ PBS group were largely reduced compared with that in the DMEM+FBS group $(3416 \pm 510.9$, $2407 \pm 301.4, P<0.05$, Figures $5 d$ and $e$ ), which implied that the cells were seriously suffering starvation accompanied with cell death. These results suggested that this in vitro culture system can mimic the in vivo neonatal transition process.

To address the function of autophagy in neonatal mouse ovary, we then blocked autophagy by adding autophagy inhibitor 3-MA into the in vitro neonatal ovary culture system. As shown in Figures $5 \mathrm{~b}$ and $\mathrm{c}$, autophagy was seriously disrupted in the DMEM+FBS+3-MA and 85\% PBS+3-MA groups after 3-MA addition. Histomorphological analysis 
a

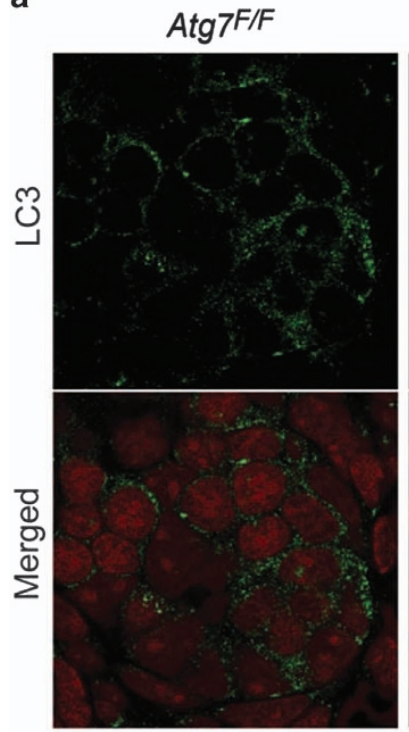

c
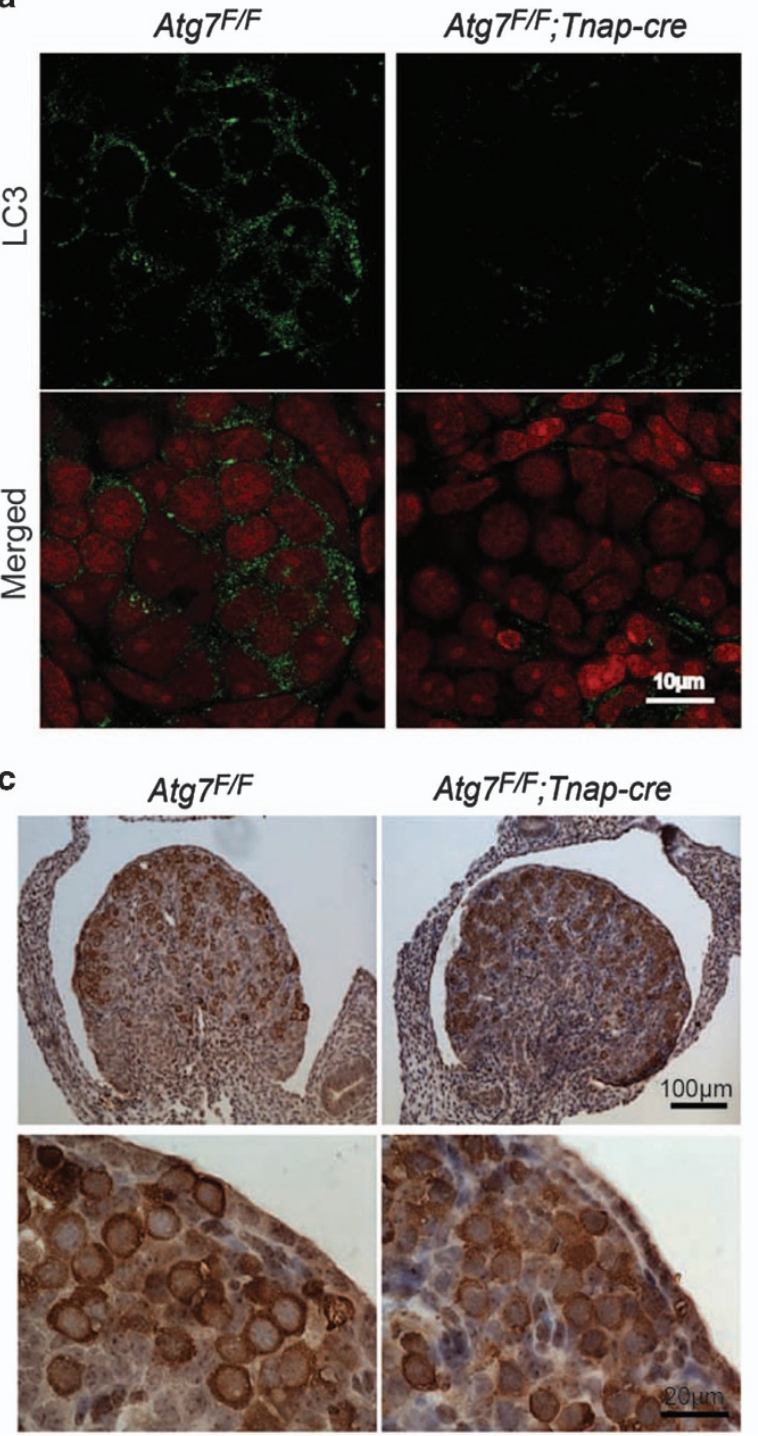

b

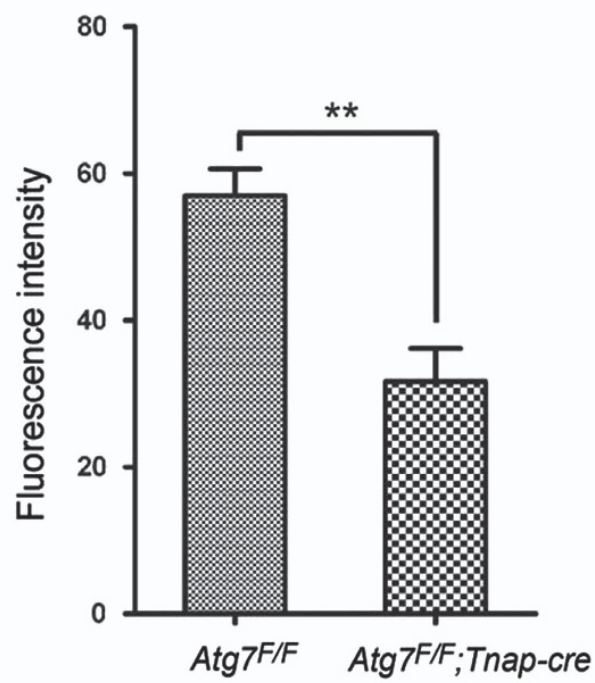

d

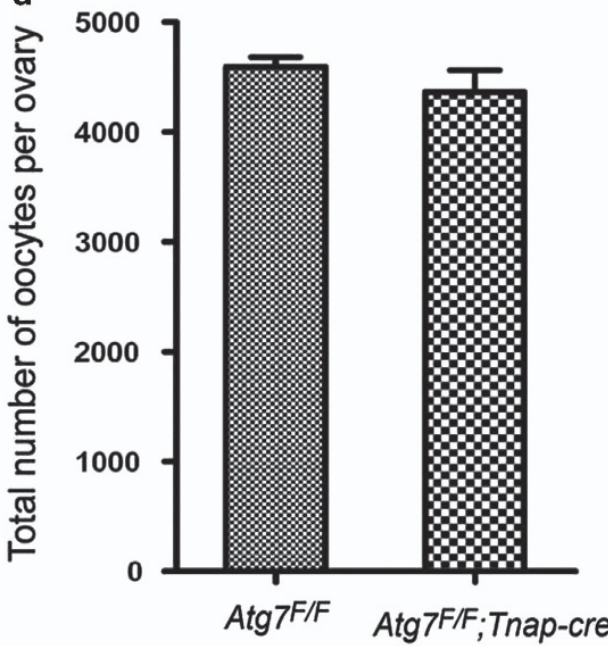

Figure 2 Atg7 knockout did not affect oocytes number in fetal ovaries on $17.5 \mathrm{dpc}$. (a) Autophagy was severely disrupted in $17.5 \mathrm{dpc} A \operatorname{Ag} 7^{\mathrm{F} / F} ; \operatorname{Tnap}$-cre mice $(n=3)$ ovaries by immunostaining of LC3. LC3 (in green), nuclear (in red). (b) Quantification of LC3 fluorescent intensity in panel (a). (c) Morphological analysis of 17.5 dpc fetal ovaries of Atg $7^{\text {F/FF }}$; Tnap-cre mice and the control. Germ cell was indicated by immunohistochemical detection of MVH. (d) Quantification of oocytes number in $17.5 \mathrm{dpc}$ fetal ovaries of Atg $7^{\mathrm{F} / F}$; Tnapcre mice $(n=3)$ and the control $(n=3)$. Data are presented as the mean \pm S.E.M. ${ }^{* *} P<0.01$

revealed that autophagy inhibition had no significant effect on the oocytes $(3416 \pm 510.5$ versus $2801 \pm 344.7)$ and follicles ( $2407 \pm 301.4$ versus $1907 \pm 325.0)$ under nutrient condition by comparing the DMEM+FBS group to the DMEM+FBS+3MA group (Figures $5 \mathrm{~d}$ and $\mathrm{e}$ ). However, in the $85 \%$ PBS+3-MA group, the oocytes $(159.3 \pm 23.41)$ and follicles $(45.33 \pm 6.741)$ were reduced drastically compared with that in the $85 \%$ PBS group $(1919.3 \pm 170.7,939.3 \pm 46.94, P<0.01$, Figures $5 d$ and e). Except the number, the morphology and structure of follicles were impaired very dramatically, and typical follicles were rarely found in the $85 \%$ PBS+3-MA group (Figure $5 d$ ). Furthermore, ovaries derived from $A \operatorname{tg} 7^{F / F}$;Tnap-cre mice were cultured using the in vitro neonatal ovary culture system. As shown in Figures $6 a$ and $b$, under the starvation condition, the oocytes $(251.7 \pm 17.43)$ and follicles $(98 \pm 12.49)$ were reduced drastically compared with that in DMEM+FBS group
$(2041 \pm 158.0,1254 \pm 115.3, P<0.01)$, which indicated that deletion of Atg7 had a similar effect of 3-MA treatment under the starvation condition. These results suggested that it is the whole autophagy machinery rather than Atg7 alone that protects germ cells' over-loss in the neonatal ovaries under the starvation condition.

\section{Autophagy inhibition leads to oocyte over-loss through} apoptosis in the in vitro cultured ovaries. In the neonatal phase in mammals, apoptosis is coupled to autophagy as a means to maintain tissue viability and energy homeostasis in developing tissues. ${ }^{32,35,36}$ To test whether inhibition of autophagy lead to germ cell over-loss through apoptosis, we examined the apoptosis process in the in vitro cultured neonatal ovaries using the TUNEL (TdT-mediated dUTP nick end labeling) staining. As shown in Figures $7 a$ and b, under 


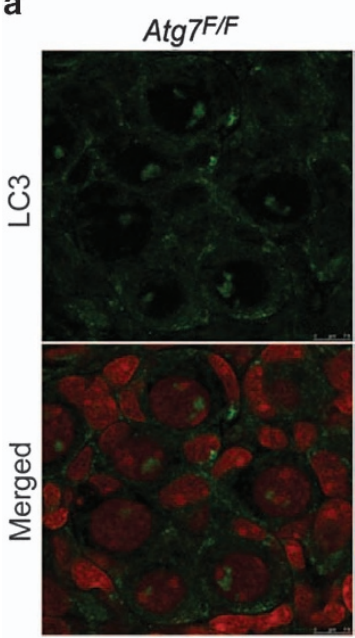
Atg7F/F;Tnap-cre

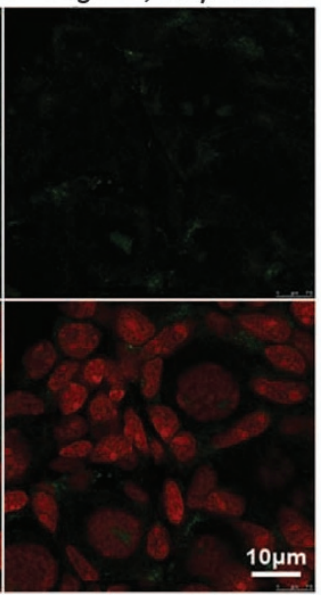

C

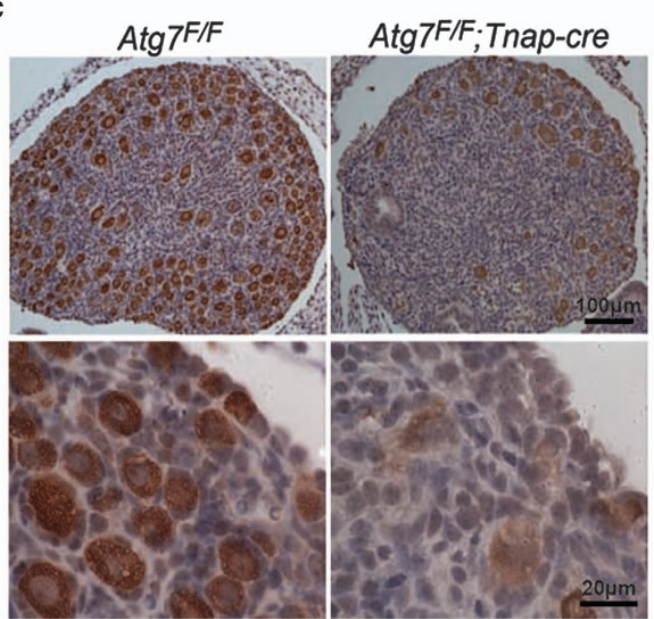

b

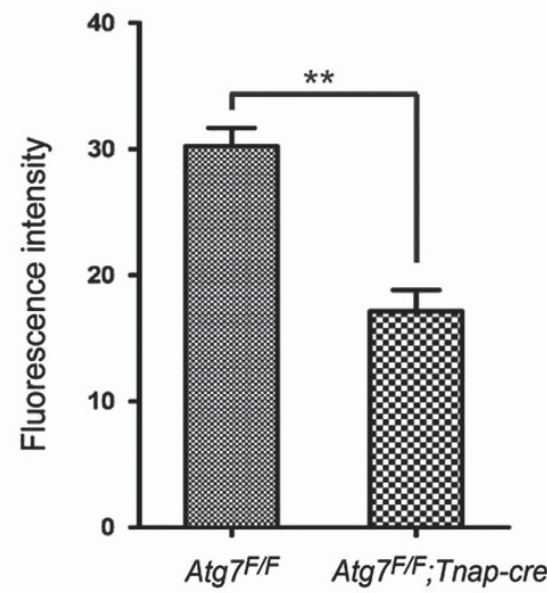

d

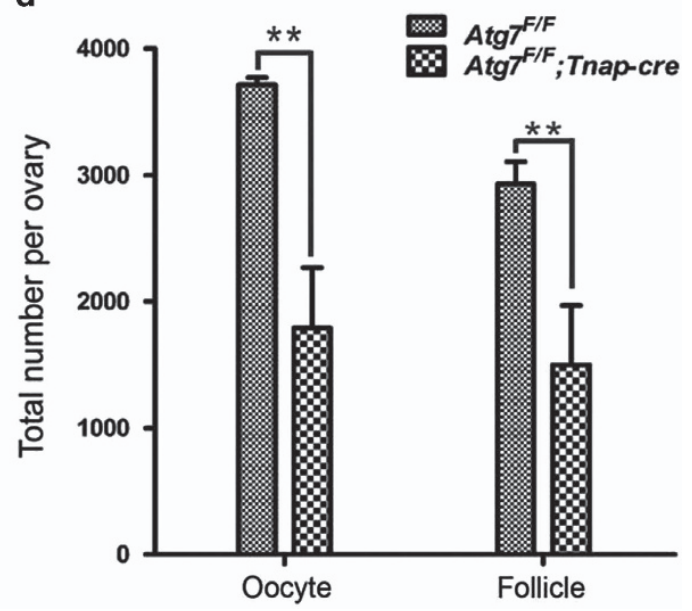

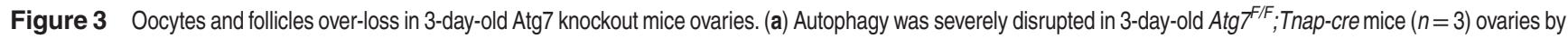
immunostaining of LC3. LC3 (in green), nucleus (in red). (b) Quantification of LC3 fluorescent intensity in panel (a). (c) Morphological analysis of 3-day-old ovaries after Atg7 knockout. Germ cell was indicated by immunohistochemical detection of MVH. (d) Quantification of oocyte and follicle numbers in 3-day-old mice ovaries of Atg ${ }^{F / F}$; Tnap-cre mice $(n=3)$ and the control $(n=3)$. Oocytes at least surrounded by three cells were counted as follicles. Data are presented as the mean \pm S.E.M. ${ }^{* *} P<0.01$

the nutrient condition, although the ovaries contained some TUNEL-positive oocytes, there was no significant difference between the DMEM+FBS group and the DMEM+FBS+3-MA group. In accordance with the oocyte/follicle loss results, the percentage of TUNEL-positive oocytes was increased significantly in the $85 \%$ PBS group compared with the DMEM+ FBS group. Once autophagy was inhibited under starvation condition, the amount of TUNEL-positive oocytes was significantly increased in comparison to the $85 \%$ PBS group, about $80 \%$ oocytes died by apoptosis. Furthermore, the broad-spectrum caspase inhibitor Z-VAD-FMK $(100 \mu \mathrm{M})$ was used to block apoptosis in the 85\% PBS+3-MA group. Fortunately, the continuous presence of Z-VAD-FMK in the culture medium delayed or inhibited the death of oocytes (Figure 7c), and the number of oocytes (1043 \pm 197.2$)$ and follicles $(454.7 \pm 105.3)$ were increased drastically compared with that in the $85 \%$ PBS+3-MA group $(271.7 \pm 70.72$, $73.33 \pm 15.07, P<0.05$, Figure $7 d$ ). These results suggested that inhibition of autophagy lead to oocyte over-loss through apoptosis in the in vitro cultured ovaries under starvation condition.

\section{Discussion}

Although a lot of genes have been found to be associated with $\mathrm{POI}$, as a complex disorder, POI may have a number of different genetic etiologies. Actually, defects in the development of PGCs, meiosis, follicle formation, follicular activation and follicular development could all cause POI. ${ }^{37}$ In the present study, we found that germ cell-specific Atg7 knockout led to subfertility in female mice. Similar to POI in human patients, the pool of ovarian follicles decreased dramatically in Atg7 knockout mice, thus mutations of Atg7 or defects of autophagic machinery might be the etiology of POI.

Further study revealed that oocyte over-loss of Atg7 knockout mice occurred during the neonatal transition period. The massive germ cell loss shortly after parturition is a mysterious phenomenon in the reproductive biology, and our research might provide a plausible explanation to this 
a
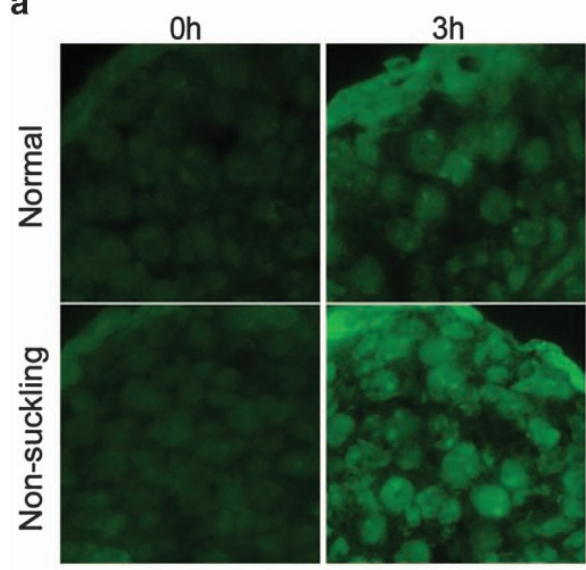

b

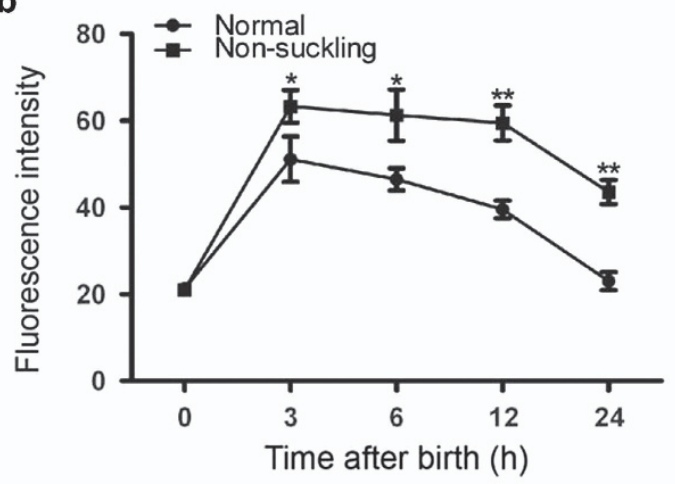

d

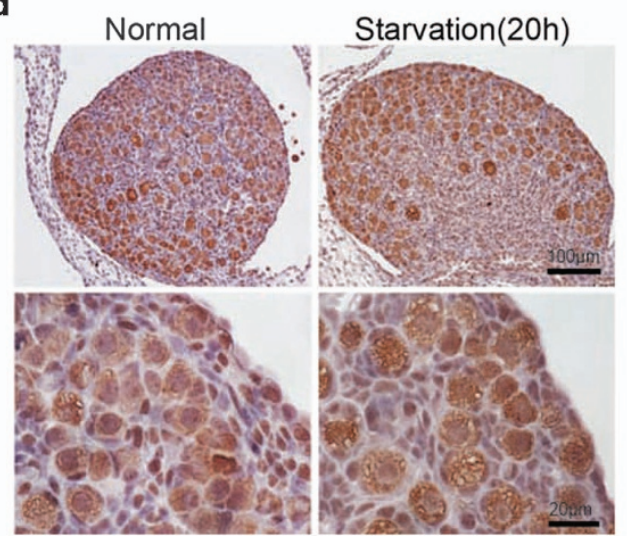

$6 h$

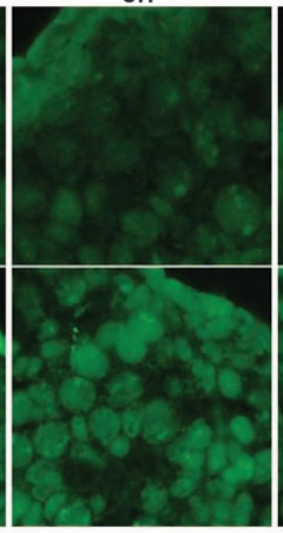

C
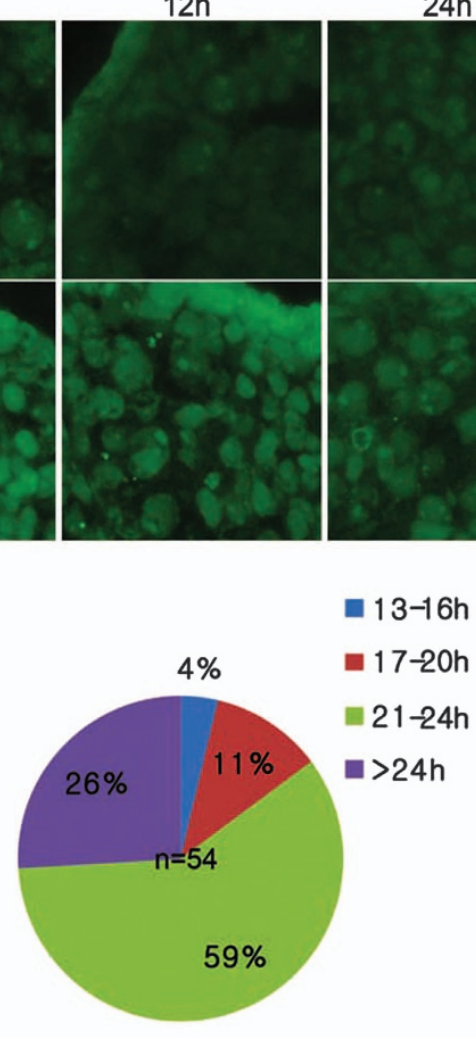

e

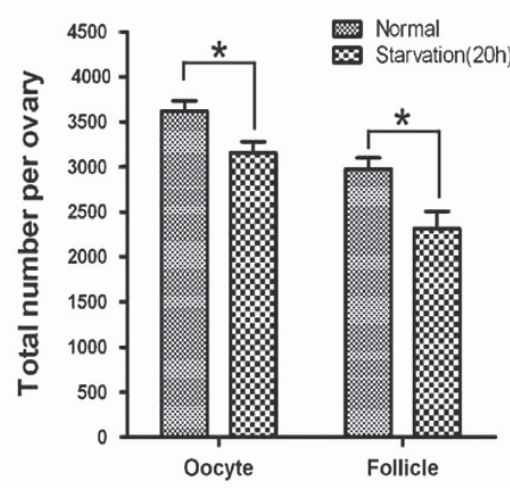

Figure 4 Autophagy was induced in mice ovary during neonatal transition. (a) Autophagy induction in the neonatal ovary indicated by immunostaining of LC3 (in green). In the non-suckling groups, mice were separated from the mother immediately after birth. Ovaries were isolated from mice at $0,3,6,12$ and $24 \mathrm{~h}$, immediately fixed, cryosectioned, and analyzed by fluorescence microscopy. (b) Quantification of LC3 fluorescent intensity in panel (a). Asterisks indicate statistically significant difference in comparison with the normal group. (c) Survival time of neonatal mice under non-suckling condition. Most of the neonatal mice died during 21-24 $\mathrm{h}$ after birth under non-suckling condition. The 24-h survivals were immediately killed for experiments. (d) Morphological analysis of 3 days' ovaries derived from 20-h non-suckling starvation. (e) Quantification of oocyte and follicle numbers in panel (d). Data are presented as the mean of three experiments \pm S.E.M. ${ }^{*} P<0.05,{ }^{* \star} P<0.01$

phenomenon. In placental mammals, fetus obtains nutrients from the mother through the placenta in prenatal period, which is responsible for the transfer of the bulk of substances between maternal and fetal circulations. However, this transplacental nutrient supply is suddenly interrupted after birth; neonate must start the arterial supply system. During this transition from fetal to neonatal life, neonates face severe starvation until supply can be restored through milk nutrients. ${ }^{38}$ Most of the organs adapt to this postparturition starvation by inducing autophagy, which can produce amino acids for the maintenance of energy homeostasis by autophagic degradation of 'self' proteins. ${ }^{32}$ Consistent with a previous report, ${ }^{34}$ we found that autophagy was immediately induced and reached its maximal level during 3-6 $\mathrm{h}$ after birth (Figure 4). Inhibition of autophagy by 3-MA in neonatal ovaries cultured in vitro led to severe germ cell loss in neonatal ovaries 
a

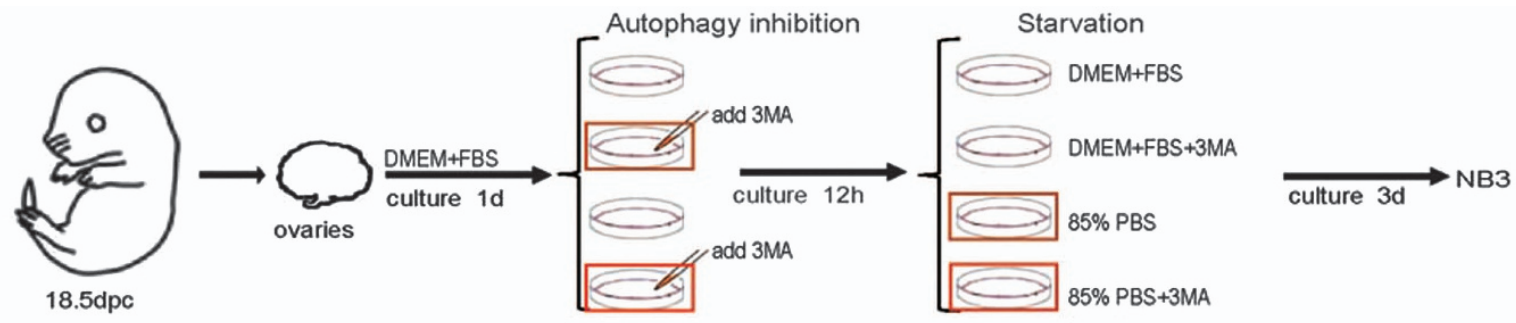

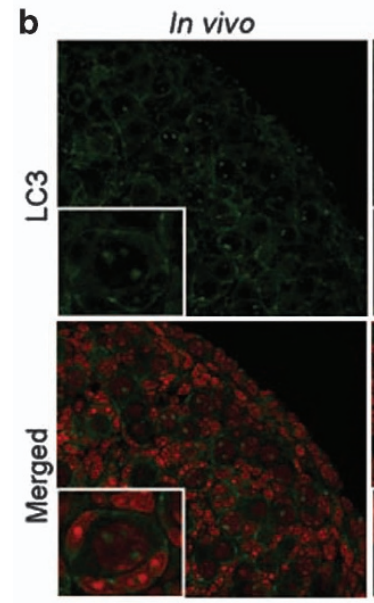

C

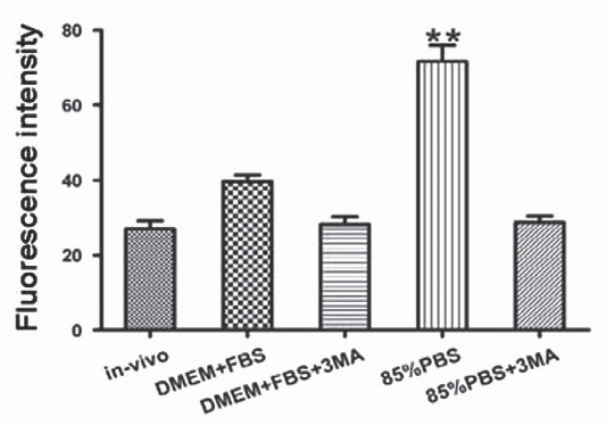

d

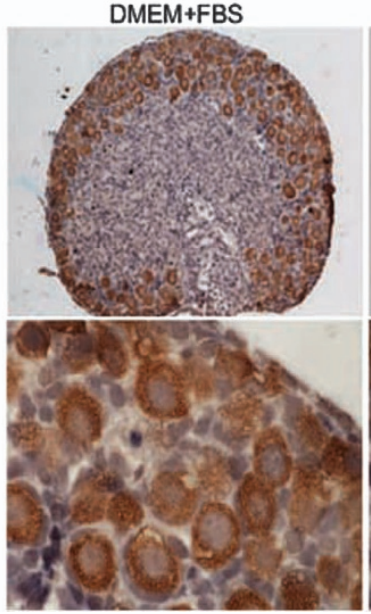

DMEM+FBS
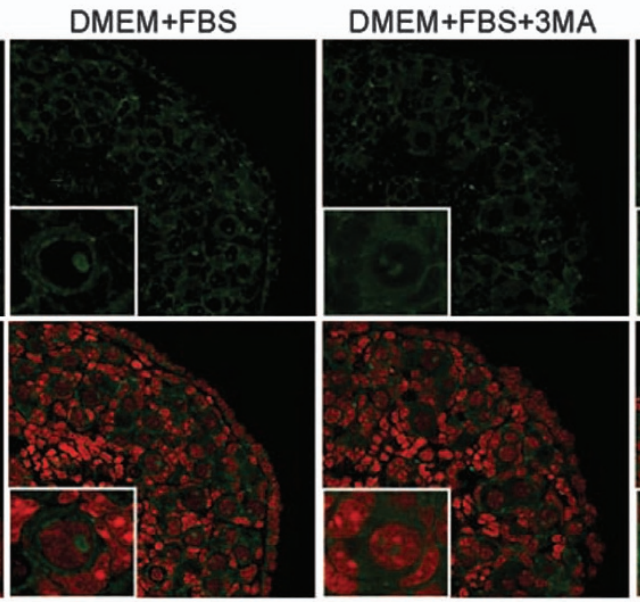

e
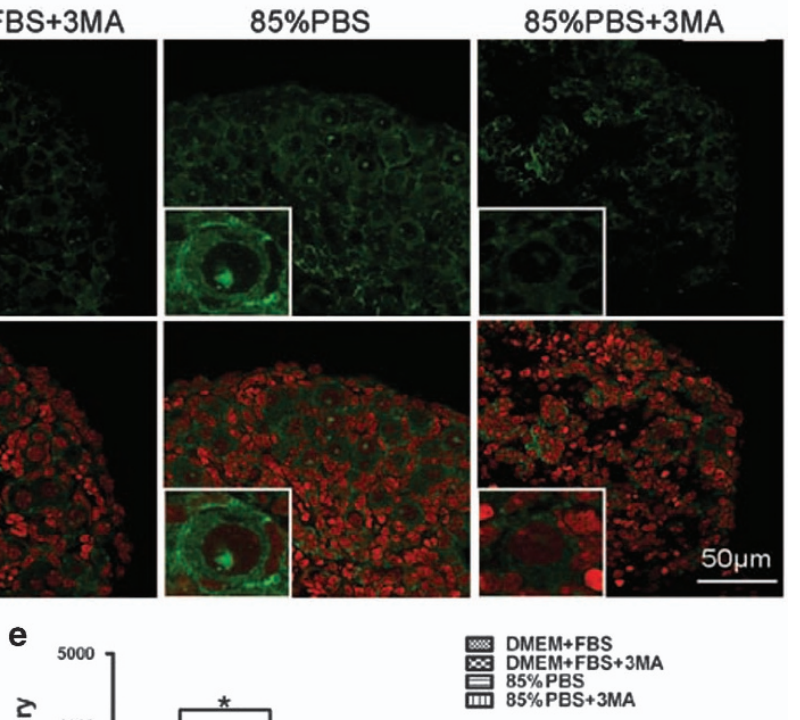

昫 $85 \%$ PBS
$85 \% \mathrm{PBS}+3 \mathrm{MA}$

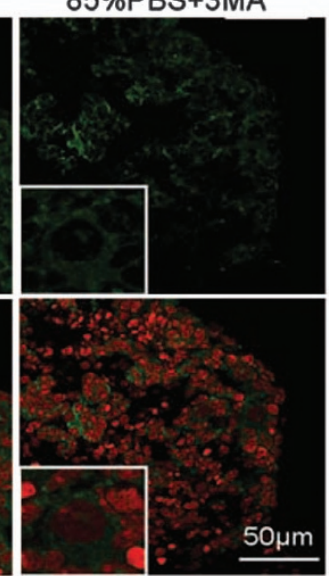

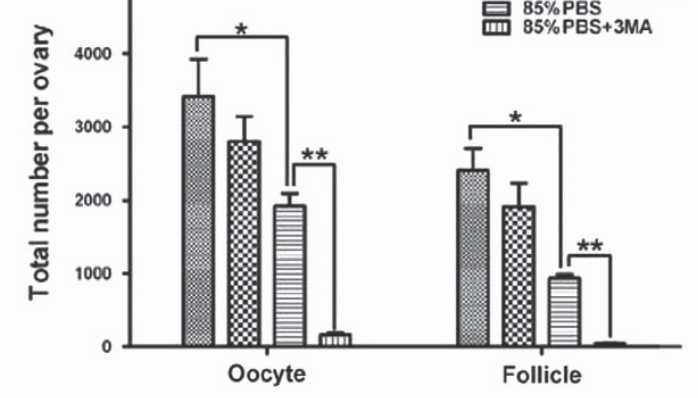

DMEM+FBS+3MA

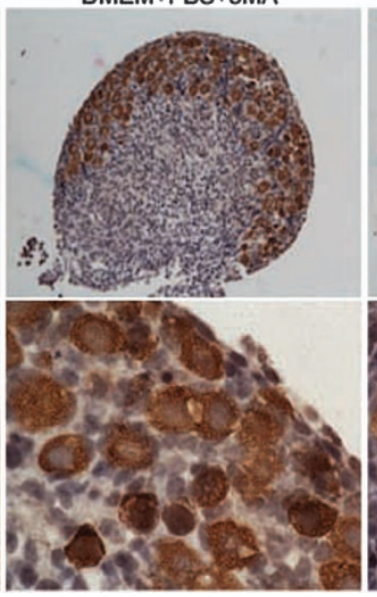

$85 \%$ PBS

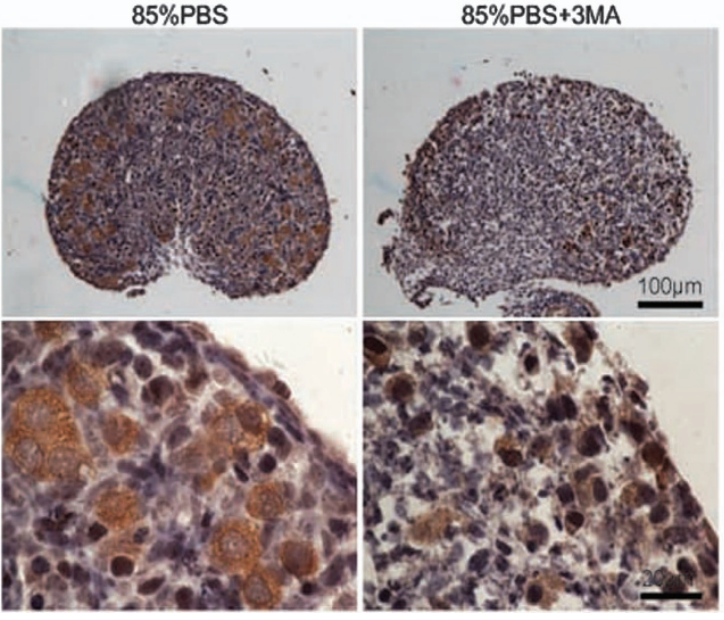

Figure 5 Autophagy protects germ cell from over-loss under starvation condition. (a) The diagram of the in vitro ovary culture experiments. Dulbecco's modified Eagle's medium+fetal bovine serum (DMEM+FBS) group represented the rich medium. In the $85 \%$ phosphate-buffered saline (PBS) group, $85 \%$ DMEM+FBS medium were replaced by PBS to mimic the starvation condition. Autophagy was blocked by 3-MA, its final concentration was $5 \mathrm{mM}$. NB3 represented 3 days after birth. (b) Autophagy induction indicated by immunostaining of LC3 in in vitro cultured neonatal ovaries. LC3 (in green), nuclear (in red). In vivo group represents the ovary derived from the 3-day-old mice. (c) Quantification of LC3 fluorescent intensity in panel (b). (d) Morphological analysis of 3 days in vitro cultured ovaries. Germ cell was indicated by immunohistochemical detection of MVH. (e) Quantification of oocytes and follicles numbers in 3 days in vitro cultured neonatal ovaries. Oocytes surrounded at least by three cells were counted as follicles. Data are presented as the mean of three experiments \pm S.E.M. ${ }^{\star} P<0.05,{ }^{\star *} P<0.01$ 
a

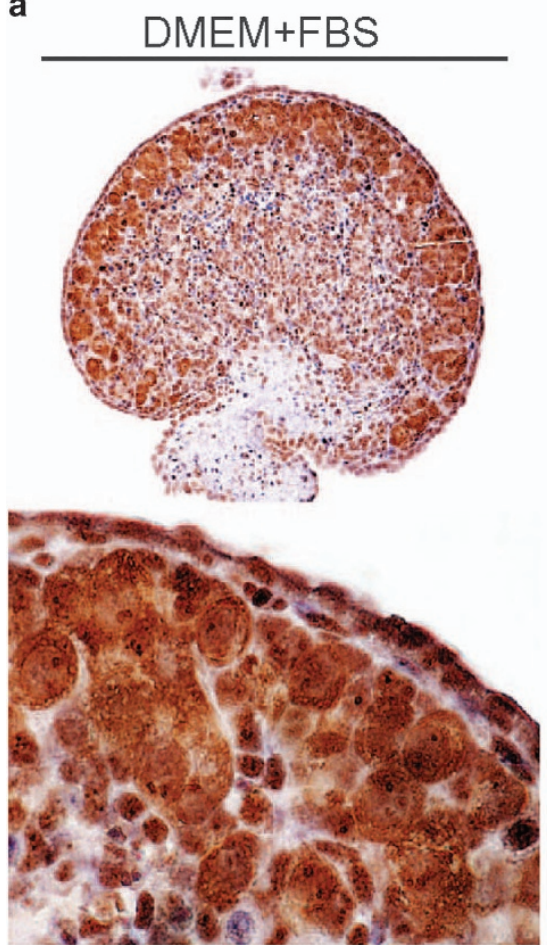

$85 \%$ PBS
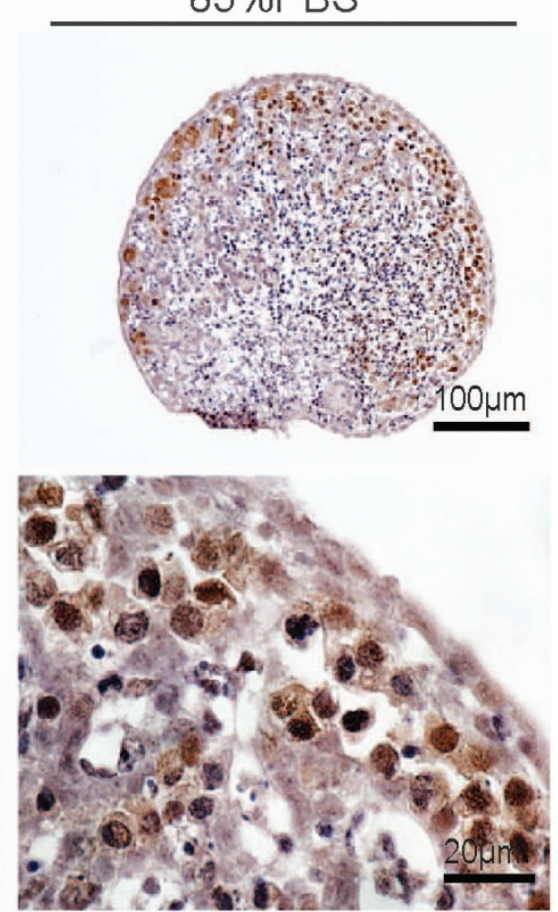

b

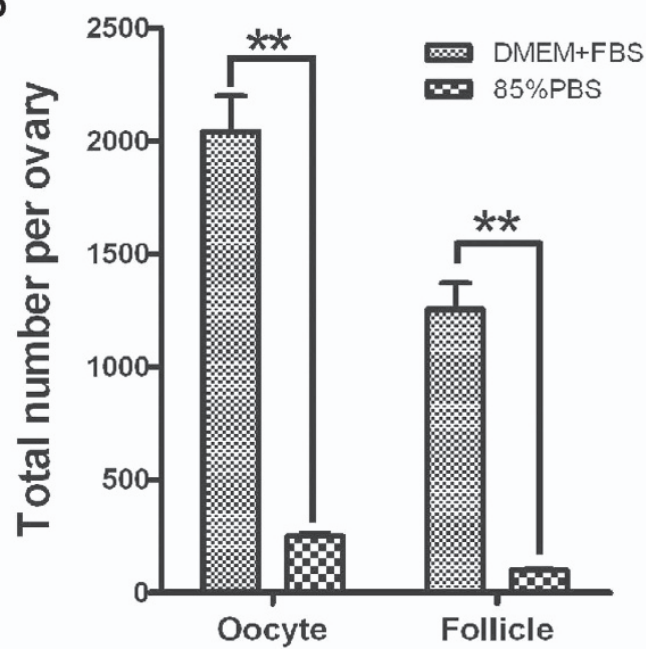

Figure 6 Deletion of Atg7 causes germ cell over-loss under in vitro starvation condition. (a) Morphological analysis of Atg $7^{\mathrm{F} / F}$;Tnap-cre ovaries cultured for 3 days in vitro. (b) Quantification of oocyte and follicle numbers in 3 days in vitro cultured $A \operatorname{tg} 7^{F / F} ;$ Tnap-cre ovaries. Data are presented as the mean of three experiments \pm S.E.M. ${ }^{\star *} P<0.01$

under starvation condition (Figure 5). Hence, germ cells might be sensitive to starvation condition, and the abrupt energy homeostasis shifting during neonatal transition causes massive germ cell loss.

Interestingly, only the ovaries exhibit severe cell loss at birth among the organ systems. ${ }^{22,39,40}$ A number of studies have shown that adult stem cells in different tissues have important roles in tissue homeostasis, such as spermatogonial stem cells continuously producing differentiated progeny in testis. ${ }^{41,42}$ However, the terminally differentiated oocytes are unable to propagate themselves. ${ }^{43}$ Thus only the ovary exhibits profound cell loss at birth among the organ systems.
During the neonatal transition, autophagy helps the germ cell to overcome the early neonatal starvation, which can protect germ cell from over-loss in the neonatal ovaries.

The function of autophagy in oocytes during the neonatal transition has been implicated in some previous research; in the spiny mouse, autophagy is found to be involved in follicular atresia and observed in dying oocytes of all follicle types, especially of the primordial and primary ones. ${ }^{44}$ And multiple perinatal mechanisms, including the autophagy process, are found to establish the primordial follicle reserve in murine ovary. ${ }^{34,45}$ Although it is found that autophagy is not required for egg development in Drosophila germline cells, most likely 
a

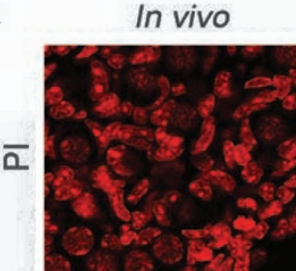

\section{DMEM+FBS}

DMEM+FBS+3MA
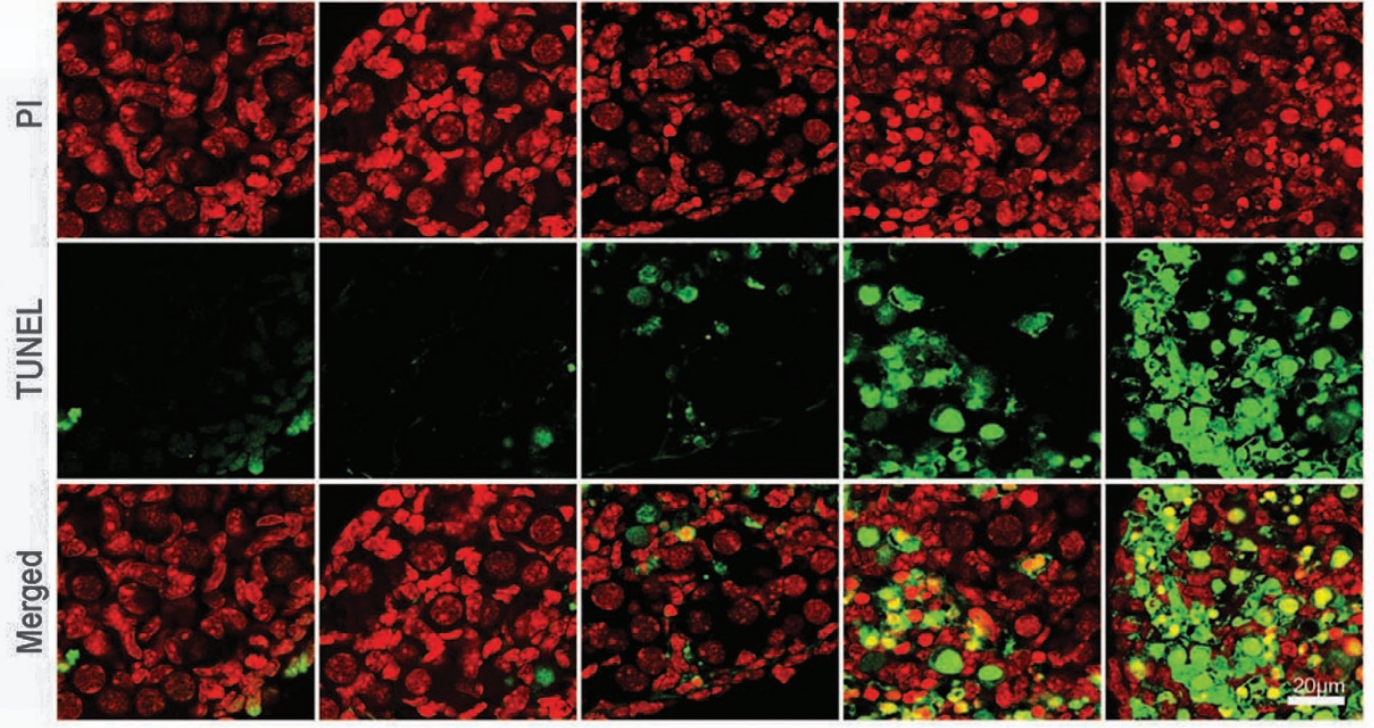

$*$
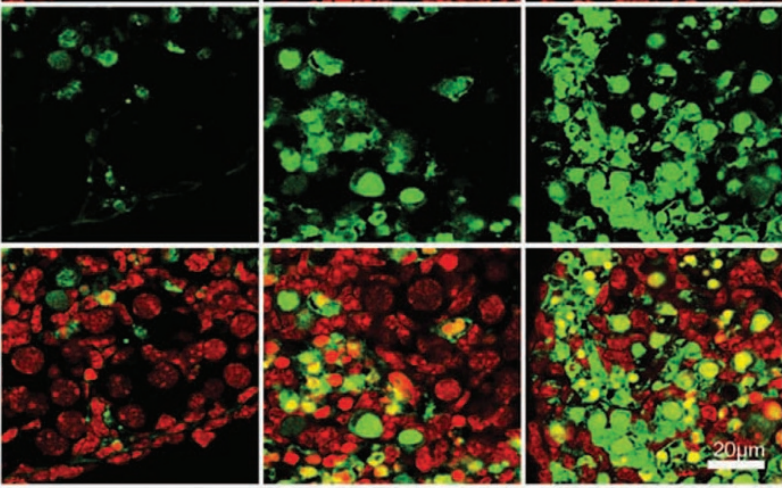

b

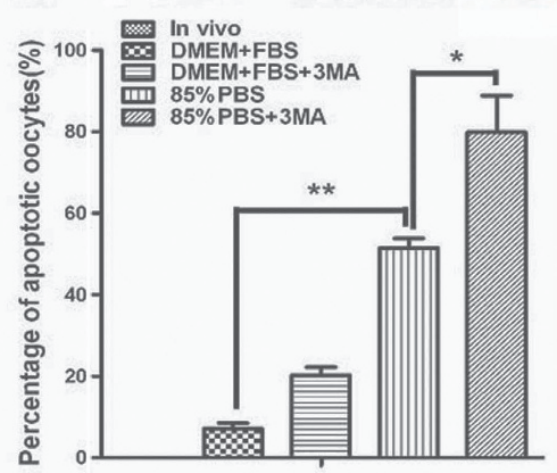

C

85\%PBS+3MA

$85 \%$ PBS+3MA+Z-VAD-FMK
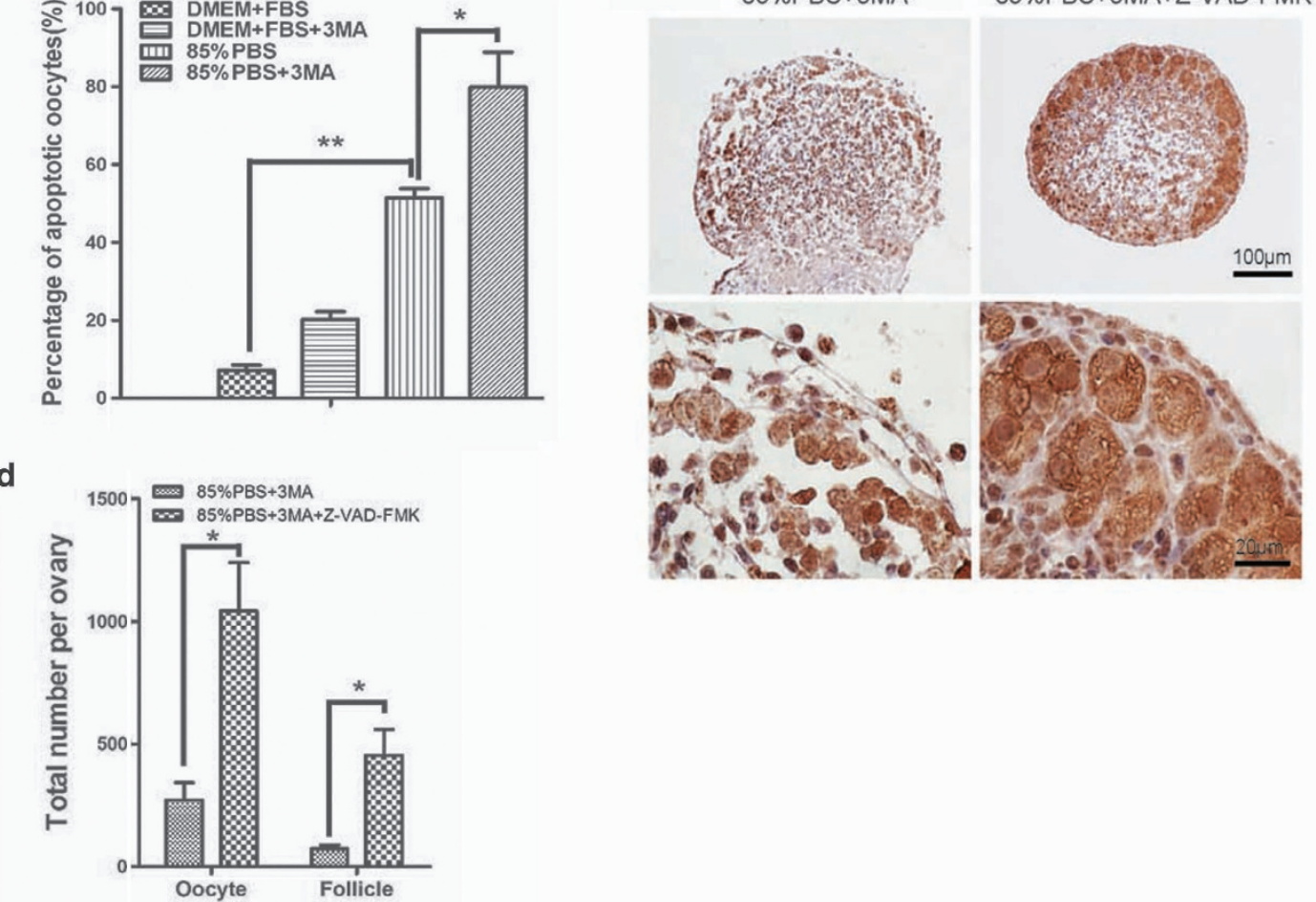

Figure 7 Inhibition of autophagy led to oocytes over-loss through apoptosis under starvation condition. (a) In vitro cultured ovarian tissues were stained by TUNEL. TUNEL signal (in green), nucleus (in red). (b) Percentages of TUNEL-positive oocytes. (c) Morphological analysis of 3 days ovaries derived from in vitro cultured with or without caspase inhibitor. (d) Quantification of the oocyte and follicle numbers in panel (c). Data are presented as the mean of three experiments \pm S.E.M. ${ }^{*} P<0.05,{ }^{* *} P<0.01$

due to the absence of neonatal transition, autophagy still could be induced by starvation in either germline cells or follicle cells in Drosophila ovaries. ${ }^{46}$ In mammalian ovaries, the functional role of autophagy in folliculogenesis is limited in germ cells but not granulosa cells, because granulosa cell-specific knockout either $\operatorname{Atg} 7$ (unpublished data) or Becn1 has no effect on folliculogenesis at all; the granulosa cell-specific Becn1 ablation results in progesterone production impairment, which led to a subsequent preterm labor phenotype. ${ }^{47}$ Thus, the role of autophagy involved in folliculogenesis is cellular and developmental stage specific.

There are at least two ways to regulate intracellular metabolite supply. One is the acquisition of extracellular nutrients, which can be regulated by growth factor signaling pathways, including the PI3K/Akt system. The other is the activation of intracellular catabolic metabolism to degrade 
intracellular macromolecules; autophagy is the most extreme form of catabolic pathways. ${ }^{36}$ In general, when growth factors are rich, the growth factor signaling activates the PI3K/Akt pathway and its downstream effectors, mTOR to inhibit autophagy, macromolecular synthesis, ATP production and inhibition of apoptosis. ${ }^{48-50}$ On the contrary, lacking of growth factors, PI3K/Akt and downstream effectors are inactivated, which can release the inhibition of autophagy by mTOR. ${ }^{51,52}$ After autophagy induction, cytoplasmic components degraded in autophagosomes/lysosomes provide an alternative source of metabolic substrate to support ATP production and survival. It has been reported that oocyte-specific knockout some of the Pten-PI3K-Akt-Foxo3 pathway-related genes such as Pten and Foxo3 led to global primordial follicle activation. ${ }^{15,17}$ Oocyte-specific knockout Tsc1 or Tsc2 does not affect the primordial follicle pool development, but the entire pool undergoes global postnatal activation, giving rise to a syndrome of increased follicle depletion and secondary infertility similar to that observed in Pten and Foxo3. ${ }^{16,53}$ As most of these genes negatively regulate autophagy, the knockout of these genes might activate autophagy in follicles, and autophagy might also participate in primordial follicle activation. Consistent with this postulation, although there are a small amount of primordial follicles in elder Atg7 knockout mice, most of the mice are almost completely infertile, suggesting the dysfunction of these follicles. So autophagy may work as a double-edged sword in oocytes or follicles: too much results in primordial follicle activation and ends up with $\mathrm{POI}$; too low results in oocytes over-loss, which also ends up with POI. Thus autophagic level needs to be well maintained in the ovary to retain female fertility.

Taken together, our present study demonstrated that Atg7 had critical roles in ovarian reserve of primordial follicles, and germ cell-specific Atg7 knockout resulted in reproductive defects with serious follicle loss in female mice. Further investigation revealed that disruption of autophagy was responsible for this follicle loss. After Atg7 depletion, the germ cells lost protection from autophagy to overcome the neonatal starvation, which led to poor ovarian reserve of primordial follicles. In conclusion, our research highlights new mechanisms for the regulation of ovarian reserve of primordial follicles and potential pathological cause of POI in human patients.

\footnotetext{
Materials and Methods

Mice. The Atg $7^{\mathrm{F} / F}$ mouse strain (RBRC02759) was purchased from the RIKEN BioResource Center (Tokyo, Japan). Atg $7^{\mathrm{F} / F}$; Tnap-Cre mice were bred from Atg $7^{\mathrm{F} / F}$ mice and Tnap-Cre mice, which were purchased from the Jackson Laboratory (Sacramento, CA, USA, 008569). The mice were bred under controlled environmental conditions with free access, illumination was provided between 0800 and 2000 hours. All animal experiments were approved by the Animal Research Panel of the Committee on Research Practice of the University of Chinese Academy of Sciences.
}

Tissue collection and histological analysis. The ovaries were dissected immediately following euthanasia. Then they were fixed in $4 \%$ paraformaldehyde $(\mathrm{pH} 7.5)$ overnight at $4^{\circ} \mathrm{C}$, dehydrated, and embedded in paraffin, after which sections (5- $\mu \mathrm{m}$ thickness) were cut and mounted on glass slides. Following deparaffinization, the slides were stained with hematoxylin and eosin for histological analysis.

Quantification of ovarian follicles. To count the numbers of follicles, paraffin-embedded ovaries were serially sectioned at $8-\mu \mathrm{m}$ thickness and every fifth section was mounted on slides as previously described by Tilly ${ }^{54}$ in 2003. Ovarian follicles at different developmental stages were counted in collected sections of an ovary, based on the well-accepted standards established by Pedersen and Peters. ${ }^{55}$ Repetitive counting of the same follicles in every fifth section through the entire ovary was avoided by counting only follicles containing oocytes with a visible nucleolus.

Ovarian tissue isolation and in vitro culturing. Briefly, fetal mouse ovaries of $18.5 \mathrm{dpc}$ were obtained from pregnant CD-1 mice, and the morning when copulation plug was observed was designated as the $0.5 \mathrm{dpc}$. The fetal ovaries, without attached mesonephroses, were selected and cultured in $500 \mu \mathrm{l}$ basic medium (DMEM/F12, 10\% FBS (Gibco, Carlsbad, CA, USA), 1\% ITS (Sigma, St. Louis, MO, USA), 1\% penicillin/streptomycin (Sigma)) in a 24-well plate. Ovaries on 24-well plates were cultured at $37^{\circ} \mathrm{C}$ in modular incubation chambers, thoroughly infused with a gas mixture of $5 \% \mathrm{CO}_{2}$ and air. The next day, ovarian tissues were treated with the autophagy inhibitor 3-MA (Sigma, M9281), at a concentration of $5 \mathrm{mM}$. After 12-h 3-MA treatment, the medium was changed to starvation condition with replacement of $85 \%$ medium by PBS. The day at which isolated ovaries were cultured in starvation condition was defined as Day 0. Experiments were repeated at least three times. We used at least three ovaries each time for different groups. For apoptosis inhibition, caspase inhibitor Z-VADFMK (Beyotime Institute of Biotechnology, Haimen, China, C1202) was used at a concentration of $100 \mathrm{uM}$.

Immunofluorescence. Ovaries were immediately embedded in an optimum cutting temperature compound and cut in 8- $\mu \mathrm{m}$ sections using a microtomecryostat. Sections were fixed with $4 \%$ paraformaldehyde and rinsed in PBS three times ( $\mathrm{pH} 7.4$ ), treated with $0.1 \%$ Triton $\mathrm{X}-100$ for 10 min, rinsed in PBS three times, blocked in blocking buffer (3\% BSA, 10\% normal goat serum in PBS) for 30 min and then incubated with rabbit anti-LC3 polyclonal antibody (Abcam, Cambridge, UK, ab58610) at $4^{\circ} \mathrm{C}$ overnight. After three rinses in PBS, the sections were incubated with goat anti-rabbit IgG conjugated with fluorescein isothiocyanate at a dilution of 1: 200 (Zhong Shan Golden Bridge Biotechnology, Beijing, China, ZF-0311) for $30 \mathrm{~min}$ at $37^{\circ} \mathrm{C}$. Propidium iodide (PI) was used to label nuclei. Images were taken immediately using a LSM 780/710 microscope (Zeiss, Oberkochen, Germany).

Immunohistochemistry. Ovaries used for histological analysis were collected from in vitro cultured ovaries, then fixed in $4 \%$ paraformaldehyde overnight at $4{ }^{\circ} \mathrm{C}$, dehydrated and embedded in paraffin. The samples were serially sectioned at $5 \mu \mathrm{m}$ as previously described by Tilly 54 in 2003. Paraffin sections were fixed with $4 \%$ paraformaldehyde and rinsed in PBS three times. Then sections were boiled for $15 \mathrm{~min}$ in sodium citrate buffer for antigen retrieval. After blocked in blocking buffer ( $3 \% \mathrm{BSA}, 10 \%$ normal goat serum in PBS) for 30 min, sections were incubated with rabbit anti-MVH polyclonal antibody (Abcam, ab13840) at $4^{\circ} \mathrm{C}$ overnight, followed by staining with the HRP-conjugated secondary antibody. Finally, the sections were stained with $\mathrm{DAB}$ (3, $3^{\prime}$-diaminobenzidine), and the nuclei were stained with hematoxylin. To count the numbers of oocytes and follicles, every third section was mounted on slides.

TUNEL. TUNEL assays were carried out with the In Situ Cell Death Detection Kit (Roche Diagnostics, Basel, Switzerland, 11684795910) according to the manufacturer's instructions. Briefly, sections of ovaries were heated at $60^{\circ} \mathrm{C}$ for $2 \mathrm{~h}$ followed by washing in xylene and rehydration through a graded series of ethanol and double distilled water. Then sections were treated with proteinase $\mathrm{K}$ for $15 \mathrm{~min}$ at room temperature and rinsed twice with PBS. After the TUNEL reaction mixture was added, slides were incubated in a humidified atmosphere for $60 \mathrm{~min}$ at $37^{\circ} \mathrm{C}$ in the dark. Finally, the sections were stained with PI.

Statistical analysis. All experiments were repeated at least three times, representing the mean \pm S.E.M., within an individual experiment. The differences between the treatment and control groups were analyzed by ANOVA, and differences were calculated by the Tukey's test. The data were considered significant when the $P$-value was $<0.05\left(^{*}\right)$ or $<0.01\left(^{* *}\right)$.

\section{Conflict of Interest}

The authors declare no conflict of interest.

Acknowledgements. We are grateful to Tomoki Chiba for providing Atg Flox/Flox $^{\text {F }}$ mice. This work was supported by the Major Basic Research Program (Grant No. 
2012CB944404), the National Natural Science Foundation of China (Grant No. 31171374 ) and the Knowledge Innovation Program of Chinese Academy of Science (Grant No. KSCX2-YW-N-071).

1. Coulam $\mathrm{CB}$, Adamson SC, Annegers JF. Incidence of premature ovarian failure. Obstet Gynecol 1986; 67: 604-606.

2. Goswami D, Conway GS. Premature ovarian failure. Hum Reprod Update 2005; 11 391-410.

3. Aittomäki K, Dieguez Lucena J, Pakarinen P, Sistonen P, Tapanainen J, Gromoll J et al. Mutation in the follicle-stimulating hormone receptor gene causes hereditary hypergonadotropic ovarian failure. Cell 1995; 82: 959-968.

4. Calderon FR, Phansalkar AR, Crockett DK, Miller M, Mao R. Mutation database for the galactose-1-phosphate uridyltransferase (GALT) gene. Hum Mutat 2007; 28: 939-943.

5. Cervato S, Mariniello B, Lazzarotto F, Morlin L, Zanchetta R, Radetti G et al. Evaluation of the autoimmune regulator (AIRE) gene mutations in a cohort of Italian patients with autoimmune-polyendocrinopathy- candidiasis-ectodermal-dystrophy (APECED) and in their relatives. Clin Endocrinol 2009; 70: 421-428.

6. Di Pasquale E, Beck-Peccoz P, Persani L. Hypergonadotropic ovarian failure associated with an inherited mutation of human bone morphogenetic protein-15 (BMP15) gene. Am J Hum Genet 2004; 75: 106-111.

7. Latronico AC, Anasti J, Arnhold IJ, Rapaport R, Mendonca BB, Bloise W et al. Testicular and ovarian resistance to luteinizing hormone caused by inactivating mutations of the luteinizing hormone-receptor gene. N Engl J Med 1996; 334: 507-512.

8. Marozzi A, Vegetti W, Manfredini E, Tibiletti MG, Testa G, Crosignani PG et al. Association between idiopathic premature ovarian failure and fragile X premutation. Hum Reprod 2000; 15: 197-202.

9. Perheentupa J. Autoimmune polyendocrinopathy-candidiasis-ectodermal dystrophy (APECED). Horm Metab Res 1996; 28: 353-356.

10. Persani L, Rossetti R, Cacciatore $C$. Genes involved in human premature ovarian failure. $J$ Mol Endocrinol 2010; 45: 257-279.

11. Shelling AN, Burton KA, Chand AL, van Ee CC, France JT, Farquhar CM et al. Inhibin: a candidate gene for premature ovarian failure. Hum Reprod 2000; 15: 2644-2649.

12. Wang B, Wen Q, Ni F, Zhou S, Wang J, Cao Y et al. Analyses of growth differentiation factor 9 (GDF9) and bone morphogenetic protein 15 (BMP15) mutation in Chinese women with premature ovarian failure. Clin Endocrinol 2010; 72: 135-136.

13. Wittenberger MD, Hagerman RJ, Sherman SL, McConkie-Rosell A, Welt CK, Rebar RW et al. The FMR1 premutation and reproduction. Fertil Steril 2007; 87: 456-465.

14. Flaws JA, Hirshfield AN, Hewitt JA, Babus JK, Furth PA. Effect of bcl-2 on the primordial follicle endowment in the mouse ovary. Biol Reprod 2001; 64: 1153-1159.

15. Watkins WJ, Umbers AJ, Woad KJ, Harris SE, Winship IM, Gersak K et al. Mutational screening of $\mathrm{FOXO} 3 \mathrm{~A}$ and $\mathrm{FOXO1A}$ in women with premature ovarian failure. Fertil Steril 2006; 86: 1518-1521

16. Adhikari D, Zheng W, Shen Y, Gorre N, Hämäläinen T, Cooney AJ et al. Tsc/mTORC1 signaling in oocytes governs the quiescence and activation of primordial follicles. Hum Mol Genet 2010; 19: 397-410.

17. Reddy P, Liu L, Adhikari D, Jagarlamudi K, Rajareddy S, Shen $Y$ et al. Oocyte-specific deletion of Pten causes premature activation of the primordial follicle pool. Science 2008 319: 611-613.

18. Klionsky DJ, Emr SD. Autophagy as a regulated pathway of cellular degradation. Science 2000; 290: 1717-1721.

19. Mizushima N, Ohsumi Y, Yoshimori T. Autophagosome formation in mammalian cells. Cell Struct Funct 2002; 27: 421-429.

20. Mizushima N, Levine B. Autophagy in mammalian development and differentiation. Nat Cell Biol 2010; 12: 823-830.

21. Mizushima N, Komatsu M. Autophagy: renovation of cells and tissues. Cell 2011; 147 728-741.

22. Qu X, Zou Z, Sun Q, Luby-Phelps K, Cheng P, Hogan RN et al. Autophagy gene-dependent clearance of apoptotic cells during embryonic development. Cell 2007; 128: 931-946.

23. Meijer AJ, Codogno P. Regulation and role of autophagy in mammalian cells. Int J Biochem Cell Biol 2004; 36: 2445-2462.

24. Wang $\mathrm{H}$, Wan $\mathrm{H}$, Li X, Liu W, Chen $\mathrm{Q}$, Wang $\mathrm{Y}$ et al. Atg7 is required for acrosome biogenesis during spermatogenesis in mice. Cell Res 2014; 24: 852-869.

25. Gozuacik D, Kimchi A. Autophagy as a cell death and tumor suppressor mechanism. Oncogene 2004; 23: 2891-2906.

26. Tsukada M, Ohsumi Y. Isolation and characterization of autophagy-defective mutants of Saccharomyces cerevisiae. FEBS Lett 1993; 333: 169-174.

27. Tsukamoto S, Kuma A, Murakami M, Kishi C, Yamamoto A, Mizushima N. Autophagy is essential for preimplantation development of mouse embryos. Science 2008; 321: 117-120.

28. Xie Z, Klionsky DJ. Autophagosome formation: core machinery and adaptations. Nat Cell Biol 2007; 9: 1102-1109.

29. Komatsu M, Waguri S, Ueno T, Iwata J, Murata S, Tanida I et al. Impairment of starvationinduced and constitutive autophagy in Atg7-deficient mice. J Cell Biol 2005; 169: 425-434.
30. Lomelí H, Ramos-Mejía V, Gertsenstein M, Lobe CG, Nagy A. Targeted insertion of Cre recombinase into the TNAP gene: excision in primordial germ cells. Genesis 2000; 26: 116-117.

31. Kabeya Y, Mizushima N, Ueno T, Yamamoto A, Kirisako T, Noda T et al. LC3, a mammalian homologue of yeast Apg8p, is localized in autophagosome membranes after processing. EMBO J 2000; 19: 5720-5728.

32. Kuma A, Hatano M, Matsui M, Yamamoto A, Nakaya H, Yoshimori T et al. The role of autophagy during the early neonatal starvation period. Nature 2004; 432: 1032-1036.

33. Shen W, Zhang D, Qing T, Cheng J, Bai Z, Shi Y et al. Live offspring produced by mouse oocytes derived from premeiotic fetal germ cells. Biol Reprod 2006; 75: 615-623.

34. Rodrigues $\mathrm{P}$, Limback D, McGinnis LK, Plancha CE, Albertini DF. Multiple mechanisms of germ cell loss in the perinatal mouse ovary. Reproduction 2009; 137: 709-720.

35. Yu L, Lenardo MJ, Baehrecke EH. Autophagy and caspases: a new cell death program. Cell Cycle 2004; 3: 1122-1124.

36. Lum JJ, DeBerardinis RJ, Thompson CB. Autophagy in metazoans: cell survival in the land of plenty. Nat Rev Mol Cell Biol 2005; 6: 439-448.

37. Jagarlamudi K, Reddy P, Adhikari D, Liu K. Genetically modified mouse models for premature ovarian failure (POF). Mol Cell Endocrinol 2010; 315: 1-10.

38. Medina JM, Vicario C, Juanes M, Fernández E. Biochemical adaptations to early extrauterine life. In: Herrera E, Knopp R (eds). Perinatal Biochemistry. CRC Press: Boca Raton, FL, USA, 1992. pp 233-258.

39. Reynaud K, Driancourt M. Oocyte attrition. Mol Cell Endocrinol 2000; 163: 101-108.

40. Tilly JL. Commuting the death sentence: how oocytes strive to survive. Nat Rev Mol Cell Biol 2001; 2: 838-848.

41. Kent Hamra F, Schultz N, Chapman KM, Grellhesl DM, Cronkhite JT, Hammer RE et al. Defining the spermatogonial stem cell. Dev Biol 2004; 269: 393-410.

42. Guan K, Nayernia K, Maier LS, Wagner S, Dressel R, Lee JH et al. Pluripotency of spermatogonial stem cells from adult mouse testis. Nature 2006; 440: 1199-1203.

43. Gheorghisan-Galateanu AA, Hinescu ME, Enciu AM. Ovarian adult stem cells: hope or pitfall? J Ovarian Res 2014; 7: 71-78.

44. Hulas-Stasiak M, Gawron A. Follicular atresia in the prepubertal spiny mouse (Acomys cahirinus) ovary. Apoptosis 2011; 16: 967-975.

45. Gawriluk TR, Hale AN, Flaws JA, Dillon CP, Green DR, Rucker EB. Autophagy is a cell survival program for female germ cells in the murine ovary. Reproduction 2011; 141 : 759-765.

46. Barth JM, Szabad J, Hafen E, Kohler K. Autophagy in Drosophila ovaries is induced by starvation and is required for oogenesis. Cell Death Differ 2011; 18: 915-924.

47. Gawriluk TR, Ko C, Hong X, Christenson LK, Rucker EB 3rd. Beclin-1 deficiency in the murine ovary results in the reduction of progesterone production to promote preterm labor. Proc Natl Acad Sci USA 2014; 111: E4194-E4203.

48. Petiot A, Ogier-Denis E, Blommaart EF, Meijer AJ, Codogno P. Distinct classes of phosphatidylinositol 3'-kinases are involved in signaling pathways that control macroautophagy in HT-29 cells. J Biol Chem 2000; 275: 992-998.

49. Plas DR, Talapatra S, Edinger AL, Rathmell JC, Thompson CB. Akt and Bcl-xL promote growth factor-independent survival through distinct effects on mitochondrial physiology. J Biol Chem 2001; 276: 12041-12048.

50. Rathmell JC, Fox CJ, Plas DR, Hammerman PS, Cinalli RM, Thompson CB. Akt-directed glucose metabolism can prevent Bax conformation change and promote growth factor-independent survival. Mol Cell Biol 2003; 23: 7315-7328.

51. Blommaart EF, Luiken JJ, Blommaart PJ, van Woerkom GM, Meijer AJ. Phosphorylation of ribosomal protein $\mathrm{S} 6$ is inhibitory for autophagy in isolated rat hepatocytes. J Biol Chem 1995; 270: 2320-2326.

52. Noda T, Ohsumi Y. Tor, a phosphatidylinositol kinase homologue, controls autophagy in yeast. J Biol Chem 1998; 273: 3963-3966.

53. Adhikari D, Flohr G, Gorre N, Shen Y, Yang H, Lundin E et al. Disruption of Tsc2 in oocytes leads to overactivation of the entire pool of primordial follicles. Mol Hum Reprod 2009; 15: $765-770$.

54. Tilly JL. Ovarian follicle counts—not as simple as 1, 2, 3. Reprod Biol Endocrinol 2003; 1: 11.

55. Pedersen T, Peters $H$. Proposal for a classification of oocytes and follicles in the mouse ovary. J Reprod Fertil 1968; 17: 555-557.

Cell Death and Disease is an open-access journal published by Nature Publishing Group. This work is licensed under a Creative Commons Attribution 4.0 International Licence. The images or other third party material in this article are included in the article's Creative Commons licence, unless indicated otherwise in the credit line; if the material is not included under the Creative Commons licence, users will need to obtain permission from the licence holder to reproduce the material. To view a copy of this licence, visit http://creativecommons.org/licenses/by/4.0 